\title{
Deriving Species Richness, Endemism, and Threatened Species Patterns from Incomplete Distribution Data in the Bioko Island, Equatorial Guinea
}

\author{
Noelia Zafra-Calvo ${ }^{1}$, Jorge Miguel Lobo ${ }^{2}$, Fabio Suzart de Albuquerque ${ }^{1}$, \\ Francisco Cabezas ${ }^{3}$, Tíscar Espigares ${ }^{1}$, Miguel Ángel Olalla-Tárraga ${ }^{4}$, \\ Jaime Pérez del Val ${ }^{5}$, Marta Rueda ${ }^{1}$, Mauricio Velayos ${ }^{3} \&$ Miguel Ángel Rodríguez ${ }^{1, *}$
}

\author{
${ }^{1}$ Departamento de Ecología, Universidad de Alcalá, 28871, Alcalá de Henares, Madrid, Spain \\ ${ }^{2}$ Departamento de Biodiversidad y Biología Evolutiva, Museo Nacional de Ciencias Naturales (CSIC), \\ José Gutiérrez Abascal, 2, 28006, Madrid, Spain \\ ${ }^{3}$ Real Jardín Botánico, Pl. Murillo, 2, 28014, Madrid, Spain \\ ${ }^{4}$ Division of Biology, Imperial College London, Silwood Park Campus, Ascot, Berkshire, SL5 7PY, UK \\ ${ }^{5}$ Consejo Superior de Investigaciones Científicas - CSIC, Área de Cultura Científica, Serrano, 117, 28006, Madrid, Spain
}

\begin{abstract}
The knowledge of the spatial patterns of species richness and, particularly, of endemic and threatened species at the scale at which management activities take place is crucial for conservation. Yet, detailed descriptions of species' distribution areas are often lacking or incomplete, especially in the tropics. This article focuses on the African island of Bioko and uses species accumulation curves to evaluate the completeness of its biological inventory for three plant groups (ferns, monocotyledons and dicotyledons), birds and monkeys. Results showed that the current inventory is fairly complete for monkeys and birds, but only covers half of the vegetation in the island. Bioclimatic models were used to estimate the potential distribution of each species and to assemble species richness patterns for each taxa and for endemic and threatened species, revealing that montane and lowland rainforests were the richest habitats, while high altitude shrubs and subalpine meadows were the poorest ones. Predicted richness values for monsoon forests were unexpectedly low for plants and birds, probably because of insufficient sampling in these areas. Additionally, the comparison of species richness patterns with the proposed delineation of protected areas for the island shows that these will cover most hotspots of species richness, endemism and threatened species, except for dicotyledonous plants and endemic birds. The potential utility of the predicted patterns for conservation priorities and initiatives in Bioko is discussed.
\end{abstract}

Key words: Bioclimatic Models, Biological Inventory, Biodiversity Patterns, Inventory Completeness, Species Accumulation Curves.

\section{Introduction}

The island of Bioko is considered a biodiversity hotspot, both within the African continent (Burgess et al. 2006) and worldwide (Myers et al. 2000). Although a number of taxonomic studies have been carried out there (e.g. Pérez del Val et al. 1994; Velayos et al. 2001; Cabezas 2006), the distribution of most species is not well known except for a few taxa (e.g. Butynski and Koster 1994; Pérez del Val 1996; Aedo et al. 1999). However, this knowledge is essential to develop effective, species-oriented conservation strategies.

\footnotetext{
${ }^{*}$ Send correspondence to: Miguel A. Rodríguez

Department of Ecology, Faculty of Biology,

University of Alcalá, 28871, Alcalá de Henares, Madrid, Spain

E-mail: miguela.rodriguez@uah.es
}

In general, the strategies for biological diversity conservation and the design of protected areas have been developed with environmental information as a surrogate for diversity (Hortal and Lobo 2006). However, this does not necessarily achieve the goals for conserving the most important target, i.e., the species (Brooks et al. 2004). The spatial distribution of species reflects the variability of the physical environment, as well as the role of historical and demographical factors that determine their population dynamics. Hence, a first step to generate an effective conservation strategy is to compile taxonomical information concerning the region under study and to document spatial patterns of diversity distributions. The challenge, though, is to obtain this information in the appropriate scale for the use of conservation managers (Harris et al. 2005). 
To obtain accurate records of species' occurrences is often difficult, even with systematic samplings in relatively reduced areas. Thus, a key problem when we want to document spatial patterns of biodiversity is the lack of good biological databases (Hortal et al. 2007), which is especially common in the case of developing, highly diverse tropical regions. Species accumulation curves are being increasingly used to solve this problem, as well as to evaluate the completeness of its biological inventory (Jiménez-Valverde et al. 2008 and references therein). Also, available data on species distributions are often biased towards particular environments and geographical areas (Hortal et al. 2007), and there have been many efforts to develop different techniques for predictive modelling capable of interpolating potential species distribution ranges from fragmented data. These techniques rely on relationships between recorded species' occurrences and environmental variables to generate potential species distribution ranges from which species richness patterns can be derived and explored. Here, we use the simplest technique (bioclimatic envelope modelling), whose properties allow to minimize the drawbacks resulting from using complex models to analyze scarce and biased distribution data, as well as the lack of reliable absence information (Jiménez-Valverde et al. 2008).

This article concentrates on the biota of the Equatorial Guinean island of Bioko, and compiles a large set of species inventories carried out for three groups of plants (ferns, monocots and dicots) and two groups of vertebrates (birds and monkeys) to generate potentially useful baseline information for strategies (Zafra-Calvo et al. 2010a) and initiatives of biodiversity conservation in this area. Our objective is threefold: 1) to assess the completeness and the bias of the existing inventories by generating species accumulation curves; 2 ) to elaborate distribution maps for all species by applying simple techniques of bioclimatic modelling; and, by crossing these maps; and 3) to obtain a first approximation to the patterns of species richness for these taxa, and for endemic and threatened species.

\section{Methods}

\section{Study area}

With a surface of $2,019 \mathrm{~km}^{2}$, and latitude and longitude coordinates between $3^{\circ} 59^{\prime}$ and $13^{\circ} 48^{\prime} \mathrm{N}$, and $8^{\circ} 26^{\prime}$ and $11^{\circ} 20^{\prime} \mathrm{E}$, respectively, the nearly rectangular island of Bioko is a province of Equatorial Guinea, located $32 \mathrm{~km}$ off the coast of Cameroon. It was formed from three extinct volcanoes which constitute the highest elevations of the island (ranging from 2,009 to 3,011 m asl). The climate is typically equatorial, with a dry season from November to March and a rainy season from April to October. However, the steep topography determines large variations in precipitation, ranging from $1,557 \mathrm{~mm}$ in the North to $10,934 \mathrm{~mm}$ in the South. The mean annual temperature varies between $26.5^{\circ} \mathrm{C}$ in the Northern coast to $12{ }^{\circ} \mathrm{C}$ in Pico Basilé, the highest peak of the island (Nosti 1942).
More than 6,000 native plant species have been estimated for the island (M. Velayos, unpublished data), which make up a mosaic of natural and semi-natural plant formations, with the secondary forests currently occupying abandoned cocoa plantations being the most widely distributed among the human-modified ones (Figure 1a). Still, despite human influences (see Zafra-Calvo et al. 2010b), the biota is very rich and hosts a high degree of endemism, particularly at the level of subspecies in the case of fauna. For example, of the 65 mammal species in the island, seven are monkeys, five of which are island endemic subspecies (Butynski and Koster 1994). There are also 191 species of birds, of which 32 are also endemic subspecies (Pérez del Val et al. 1994; Pérez del Val 1996). Until recently, $42 \%$ of the island was formally protected by two nature reserves: Pico Basilé National Park and Caldera de Luba Scientific Reserve (Figure 1a), but the national legislation for protected areas is under revision, and the new law on protected areas that will define their future status still has to be passed.

\section{Species data}

Plant data were extracted from the "Flora de Guinea Equatorial" database, an ongoing project carried out at the Real Jardín Botánico (CSIC), where all the records with precise geographical locations were obtained (details in http://www.floradeguinea.com; and Cabezas 2006). These records refer to 1,138 plant species, of which 62 are ferns (158 records), 327 monocots (715 records) and 749 dicots (1,818 records). Bird data included 104 island resident species (708 records) censused by Pérez del Val (1996) between 1988 and 1992, and monkey data with the seven species present in the island (73 records) which were surveyed by Butynski and Koster (1994) between 1986 and 1990 (species lists in Table S1 (see http://www.abecol.org. br/natureza.html)).

While for plants all record locations were available as geographical coordinates, for birds and monkeys they were depicted as points in individual species maps, which we digitized into ArcGis 9.2 to extract their coordinates. Then, we generated a UTM grid comprising 2,070 cells of $1 \times 1 \mathrm{~km}$ each, to which we referred all the records to attain a uniform matrix of species presence-only data (i.e. the zeroes in this matrix were not considered as real absences in the analysis; see below). This UTM grid also constituted our general reference for extracting all environmental data, and to perform our numerical analyses as described below.

A further step was the review of specialized sources to pinpoint the endemic and threatened taxa included in our database. This indicated that 14 species of plants and 33 species of birds had been categorized as island endemisms (Figueiredo 1994; Pérez del Val et al. 1994; Pérez del Val 1996), and that five out of the seven species of monkeys inhabiting Bioko were considered subspecies present only there (Butinsky and Koster 1994). With regard to the threatened taxa, we focused on the four 

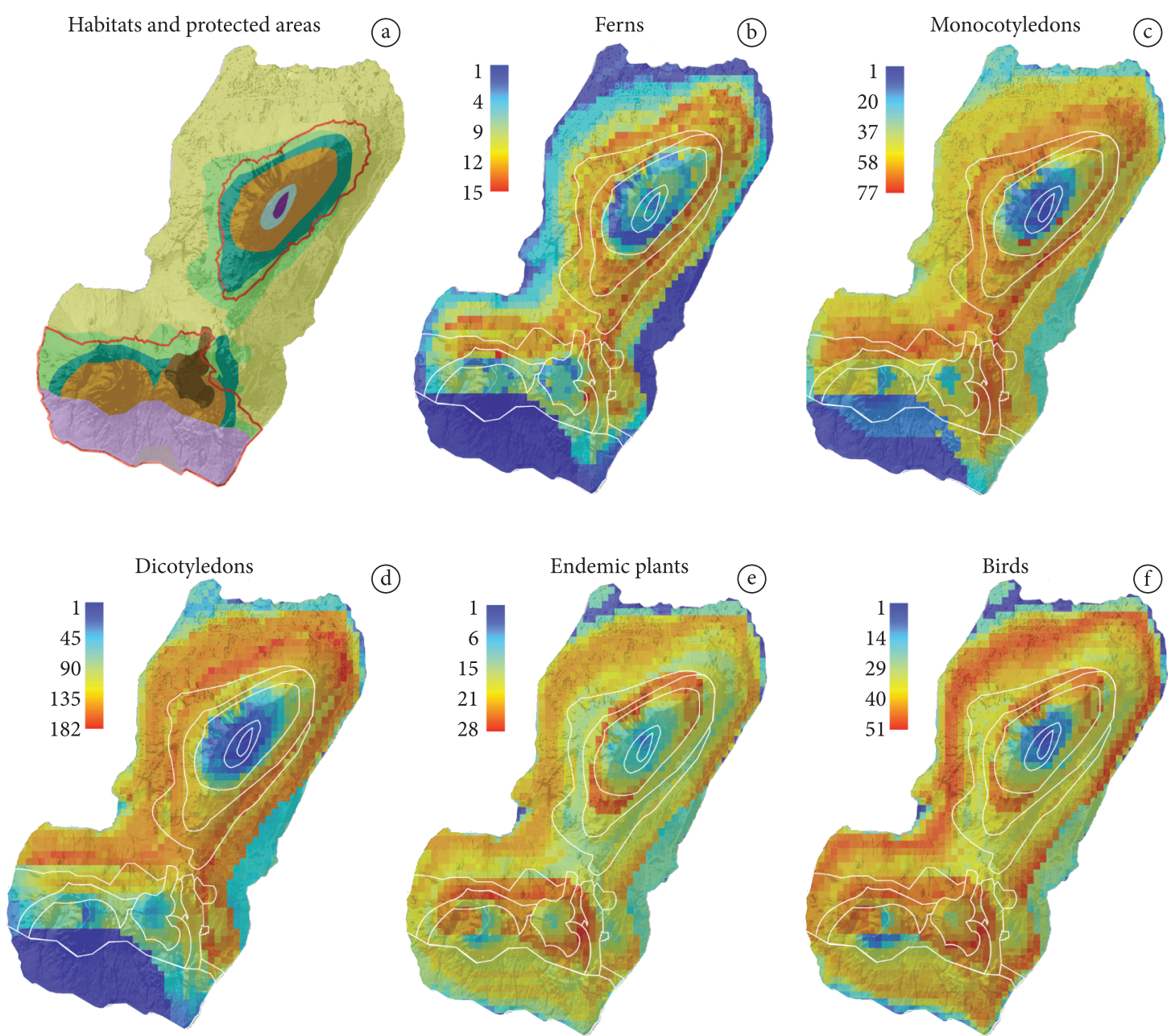

(d)
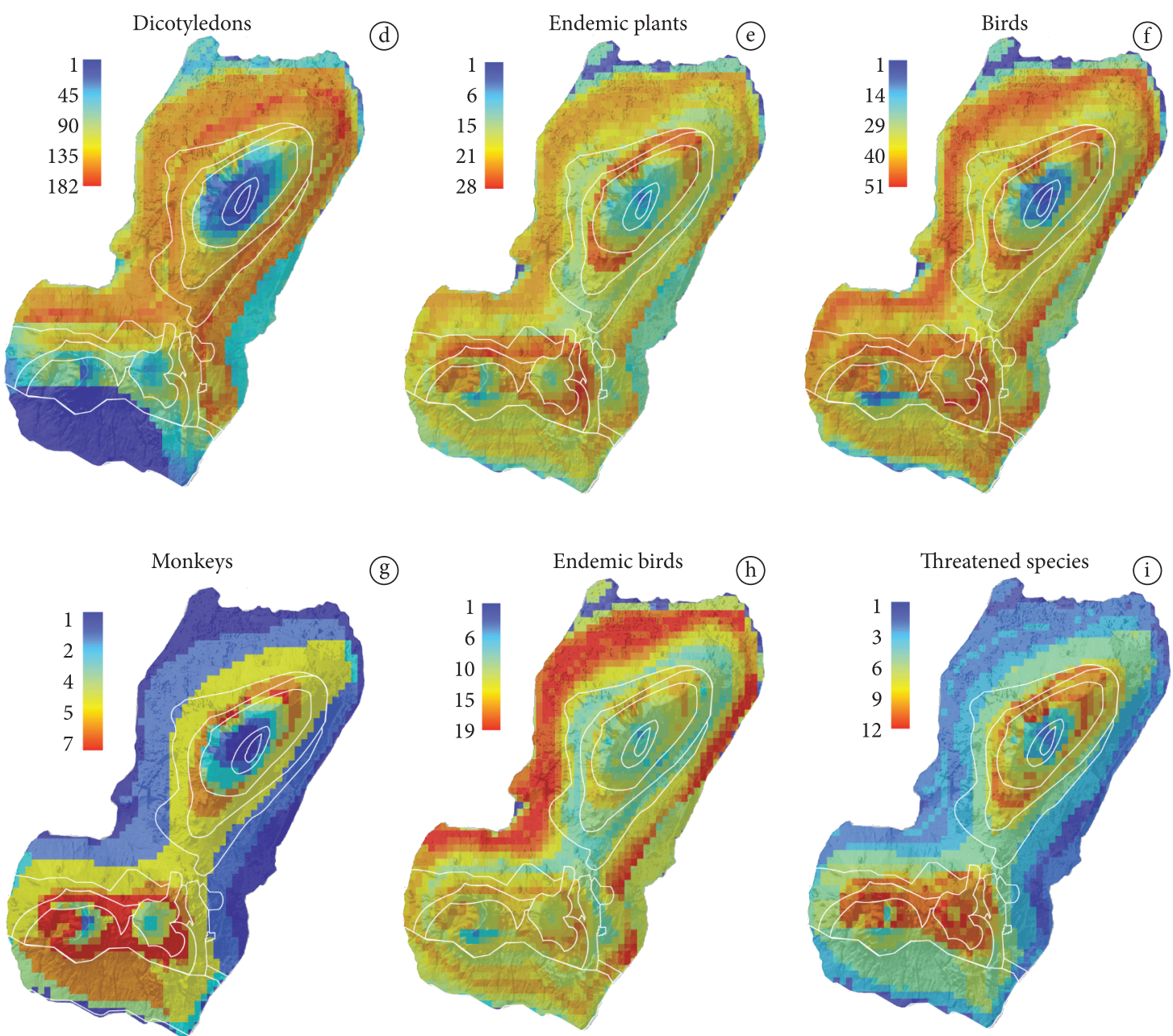

(g)
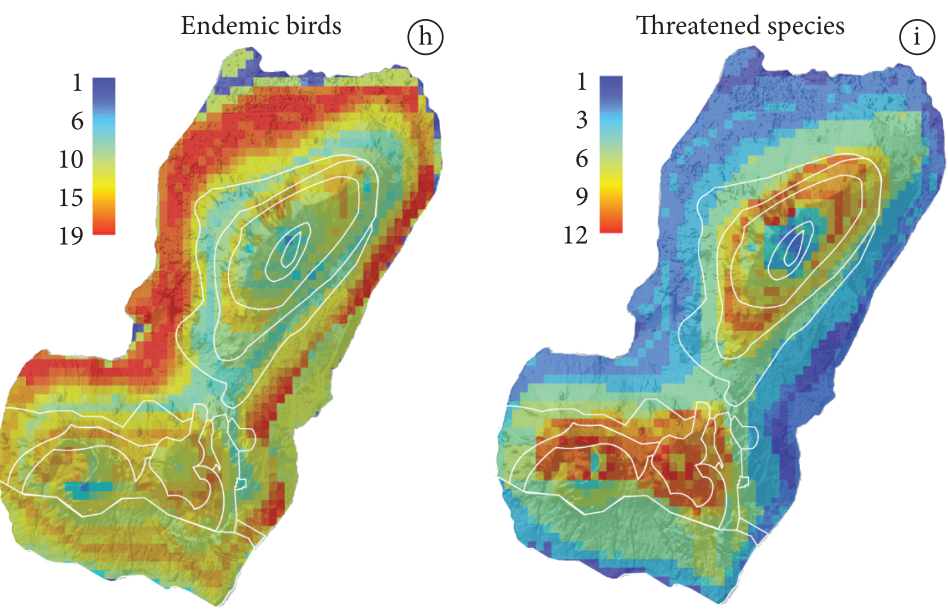

$\begin{array}{llll}\square \text { Subalpine meadow } & \square \text { Shrub formation } & \square \text { Mossy forest } & \square \text { Montane forest } \\ \square \text { Monsson forest } & \square \text { Old cocoa field } & \square \text { Grassland } & \square \text { Protected area }\end{array}$

Figure 1. a) Habitat types and proposed protected areas (red lines) in the Bioko Island, and patterns of species richness for: b) ferns, c) monocotyledons, d) dicotyledons, e) endemic plants, f) birds, g) monkeys, h) endemic birds, and i) threatened species. White lines delineate habitat boundaries in all richness maps. 
categories of the IUCN's Red List of Threatened Species (http://www.iucnredlist.org) that identify some degree of threat (i.e. near threatened, vulnerable, endangered, or critically endangered) and verified that 22 species of plants, two species of birds and five of monkeys had been included in one of them (Table S1, see http://www.abecol. org.br/natureza.html).

\section{Environmental data}

We crossed the analyzed grid cells with the WorldClim database to generate 12 climatic variables for the island; namely, annual precipitation, annual mean temperature, mean diurnal range of temperatures, isothermality, temperature seasonality, maximum temperature of the warmest month, minimum temperature of the coldest month, temperature annual range, and the mean temperatures of the wettest, driest, warmest, and coldest quarters (all technical details and data are available at: http://www.worldclim.org/; last accessed: March 2010). Also, we generated the variables elevation and slope (data extracted from a $\sim 1-k m$ resolution digital elevation model available at http:// eros.usgs.gov/\#/Find_Data/Products_and_Data_Available/ gtopo30_info; last accessed: March 2010), and the Normalized Difference Vegetation Index (obtained from the Global Change Data Archives vol. 4, included in the Additional Tools of the SIG IDRISI for the years 1981-2000). However, since redundancy among these environmental predictors is very high, we used principal component analysis to pinpoint a reduced set of predictors summarizing the environmental variability. The two first axes of this analysis had an eigenvalue $>1$ and described $92.5 \%$ of the variance, and we retained the variables that exhibited higher factor loadings as the most representative ones in the island: annual precipitation, maximum temperature of the warmest month, and minimum temperature of the coldest month.

\section{Numerical procedures}

In general, the inventory of a particular group is considered representative of its existing species richness when the number of sampled species reaches at least $70 \%$ of the estimated species (Moreno and Halffter 2000). In order to assess the degree of completeness of species inventories for ferns, monocots, dicots, birds and monkeys, we plotted, for each of these groups, cumulative numbers of species against two surrogate measures of sampling effort and then fitted them with the Clench function (e.g. Jiménez-Valverde et al. 2008) to attain species-accumulation curves. Thus, we first examined the increase in the number of species accumulated with the addition of sampling area, which we measured as the number of UTM grid cells sampled for each taxonomic group (spatial approach). And secondly, we estimated the historic growth over time of the cumulative number of recorded species from the first citations to the present time (temporal approach) (e.g. Lobo et al. 2007). The curves fitted with the Clench function reach an asymptote when the probability of adding a new species to the list approaches zero; this asymptote indicates the predicted species richness value existing in the island for the taxa being analyzed (details provided in Supplementary Online Material, SOM). Additionally, biological inventories can also be biased towards easily accessible sampling sites, for which we generated the variable accessibility to the sampling points by summing equally-weighted cell values of percent slope and average distance to main roads and tracks (details in SOM).

A bioclimatic envelope modelling-based technique, the BIOCLIM method, was used to generate predicted range distributions for all species and, by combining these ranges, predicted species richness maps for all analyzed groups. Specifically, we used Diva GIS 5.2. (available at http://www. DIVA-GIS.org; last accessed: March 2010) to cross the grid-cell presences of each species with the cell values of the three PCA-selected environmental variables (i.e. annual precipitation, maximum temperature of the warmest month, and minimum temperature of the coldest month; see above), in order to identify all the cells that lay within the range of environmental situations in which the species was recorded or, in other words, its predicted potential distribution range (Nix 1986). Bioclimatic envelope models tend to overpredict species distributions because reliable absences and distribution restrictive forces are not considered in the modelling process (Chefaoui and Lobo 2008). However, we assumed that such kind of factors will be of low relevance in a small island like this and with the fine grain resolution $(1 \mathrm{~km})$ used here (see below). Both the lack of reliable absence information and the scarce and biased presences hinder the use of more sophisticated modelling techniques (Elith et al. 2006). However, the modelling procedure we used, although being the simplest among all available techniques, is considered an appropriate mean for generating potential species distributions (Jiménez-Valverde et al. 2008), and allows overcoming the paucity of raw species distributional data for the island studied (i.e. all the well-known localities of a species are part of their distribution, as well as those with similar environmental conditions).

Finally, although paucity of survey records for most species impeded dividing the data into adequately sized training and testing samples, validation tests of omission errors conducted for 11 species with at least 15 records (details in SOM) rendered high percentages of correctly predicted presences $(82.2 \% \pm 7.8 \% \mathrm{SD})$. Regarding commission errors (failures to predict real absences), our presence-only data did not allow evaluating them, although the reduced number of points used for modelling each species, and the fine grain resolution of our modelling exercises suggest that they were very low in general (SOM).

\section{Results and Discussion}

\section{Bioko's biological inventories completeness}

In the case of our spatial approach for estimating sampling completeness, Clench accumulation curves fitted well to the observed data $\left(r^{2}>0.99\right)$ and converged to an asymptote 
in all species groups (Figure S1, see http://www.abecol. org.br/natureza.html), which made it possible to estimate the completeness of all taxonomic inventories. Thus, whereas completeness levels for plant groups (ferns: $58 \%$; monocotyledons: $54 \%$; and dicotyledons: $55 \%$ ) indicate that our data include approximately half of the species in the island, those for birds (85\%) and monkeys (81\%) are characteristic of a nearly complete biological inventory. These results are consistent with those obtained with the historical approach (Figure S2, see http://www.abecol.org. $\mathrm{br} /$ natureza.html). In this case, the cumulative number of recorded species from the first citation until now showed a poorer, but still high fit to the Clench equation for all taxonomic groups $\left(r^{2}>0.88\right)$, and the clearer asymptotic trends obtained for birds and monkeys highlighted their greater completeness compared with that of the three plant groups.

The distribution of the sampling points in relation to their accessibility suggests a strong sampling bias in the data, with most points occurring in areas with high (particularly for dicots, birds and monkeys) to moderate (monocots) accessibility (Figure 2). These results are not surprising but constitute a caution call for future surveys, which would need to pay more attention to less accessible areas if we want to attain a better representation of Bioko's biodiversity variation and, through it, to facilitate the development of more informed action plans and initiatives aimed at preserving the island's biota.

Summarizing, our data indicate that plant taxa are particularly insufficiently sampled in the island, and that the distribution of the sampling points for all groups follows a pattern influenced by accessibility. These biases, together with the existing low number of sampling records, discourage the utilization of raw biological data for describing spatial distribution patterns of species richness, so that until

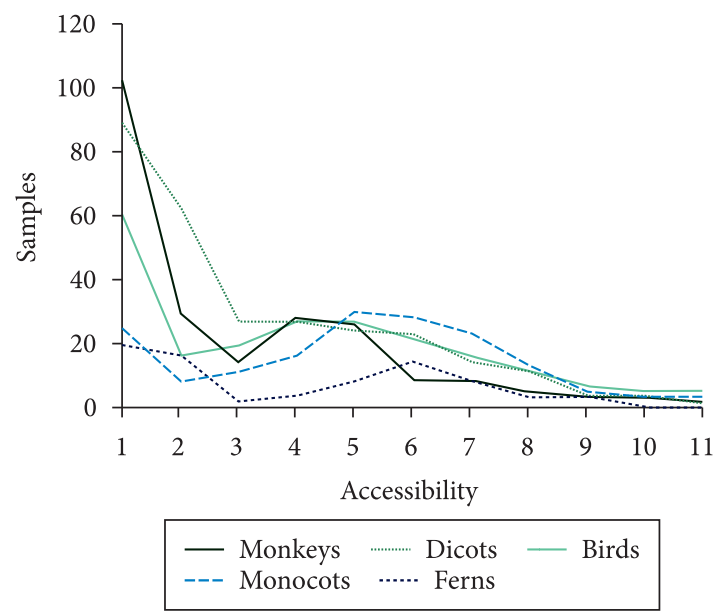

Figure 2. Distribution of the sampling points in relation to their accessibility for all taxa. The accessibility index combines both mean slopes of the sampled cells and cell average distances to main roads and tracks (more accessible sites show lower index values; see details in SOM). more exhaustive samplings are conducted, approximations based on modelling potential range distributions can be a first solution.

\section{Patterns of species richness}

We generated species richness maps for the five taxa being analyzed as well as for endemic and threatened species (Figure 1), which we visually related with the distribution of habitat types (Figure 1a). Ferns, monocots and dicots showed similar patterns (Figure $1 \mathrm{~b}-\mathrm{d}$ ), with the highest species richness values occurring in montane and lowland rainforests and, especially for dicots, in areas of secondary forest formerly occupied by cocoa plantations, an observation that has also been reported for neighbouring areas of Cameroon (Zapfack et al. 2002). Also remarkable is the fact that the three plant groups showed low species richness in the southern end of the island, surprisingly coinciding roughly with the distribution of the monsoon forests (Figure 1a). However, we suspect that these low richness values reflect a strong sampling incompleteness in monsoon forests.

Focusing on the rest of the areas, monocots and dicots (Figure 1c-d) show conspicuous spots of low species richness at the top of the three main peaks of the island, particularly in the highest one (Pico Basilé, in the north), covered by shrub formations and subalpine meadows (Figure 1a). Ferns also show low richness in these peaks (Figure 1b), but the differences with respect to the richness values occurring at adjacent lower areas are not so marked. This is consistent with observations made in other tropical mountains, and possibly reflects the greater tolerance to high altitude conditions of some of these species (Figueiredo \& Gascoigne 2001; Aldasoro et al. 2004).

With regard to the richness of endemic plants (Figure 1e), it is noticeable that the highest values are recorded at an altitude of about $1.500 \mathrm{~m}$, just below the highest peaks of the island and coinciding with the distribution of montane rainforests (Figure 1a). This high occurrence of endemic plants in montane rainforests has also been observed in similar forests of neighbouring Cameroon (Tchouto et al. 2006), and highlights that these forests are specially indicated for plant diversity protection. Also, it is remarkable that the southern part of the island (which is dominated by monsoon forests; see Figure 1a) showed higher values of endemic plant richness (Figure 1e), in clear contrast with the low total richness values of ferns, monocots and dicots that our models predicted for this area (Figure $1 \mathrm{~b}-\mathrm{d}$ ). Indeed, if such low total plant richness values were due to insufficient sampling (see above), then it seems reasonable to think that many plant endemics have also failed to be recorded in monsoon forests, and that the actual richness of endemic plants in this habitat type is much higher. This indeed reinforces the need for extra plant survey efforts in this part of the island. 
Total species richness of birds and monkeys also fall to low levels at the top of the three main elevations of the island, but increase sharply just below them, forming three well defined, ring-shaped areas of high biodiversity values (Figure 1f-g). However, both animal groups strongly differ in their patterns in lower areas. Thus, while bird richness is particularly high across the belt of abandoned cocoa plantations that are being succeeded by secondary forests, as has been observed in similar habitats in Cameroon (Peet \& Atkinson 1994) and Brazil (Faria et al. 2006), monkey richness decreases sharply in lower areas in general, except in those of monsoon forests, where it shows a clear secondary area of high biodiversity value. This possibly reflects that monkey hunting is less intense in the highly depopulated far south of the island, where bushmeat trading is likely to be less profitable due to bad communication and long distances to the main meat markets of the capital, Malabo, in the north (Albrechtsen et al. 2007).

Another noticeable pattern regarding bird distributions is the coincidence of intermediate richness values with the area covered by monsoon forests (Figure 1f). As for the case of plants, we interpret these intermediate values as a likely consequence of the difficulties of recording monsoon forest bird species, most of which are suspected to occur at the upper and more inaccessible levels of the tree canopies (J. Pérez del Val, personal observation). Again, future censuses should take into account this probable incompleteness of the bird survey of the island.

With regard to the richness patterns of endemic animals, those corresponding to monkeys (not shown) are similar to the patterns exhibited by total monkey richness, an expected result given the fact that five of the seven species inhabiting Bioko have been categorized as island endemic subspecies. A similar coincidence does not occur, however, in the case of birds, which show the highest numbers of endemic species across the belt of secondary forests ( $c f$. Peet \& Atkinson 1994), particularly in the lower areas of this habitat (Figure 1h). This result is potentially relevant for future conservation plans and initiatives, particularly if we bear in mind the delineation of the two reserve areas that are expected to be established in the island. Specifically, although the boundaries of these proposed reserves (Figure 1a) appear to encapsulate well the areas with the highest richness of threatened species (Figure 1i), they do not cover the lowlands; i.e. where the secondary forests and highest richness values of bird endemics occur (for a detailed analysis of reserve areas in the island see Zafra-Calvo et al. 2010a).

Finally, the map of threatened species richness (Figure 1i) shows clear areas of high biodiversity values at high altitudes, near the summit of the three higher peaks of Bioko, and moderate richness levels at intermediate elevations (roughly coinciding with the distribution of montane and monsoon forests). However we suspect that this prediction for monsoon forests actually constitutes another reflection of insufficient sampling in this area, and that the number of threatened species (and even of species that are currently unknown for science) is likely to be much higher there. Fortunately though, both the monsoon forest and the rest of the areas predicted to be rich in threatened species lay within the proposed delineation of protected areas for the island (Figure 1a). The challenge now is to make these areas a fully operational reality.

\section{Concluding remarks}

Although much effort has been made to document the distribution of biodiversity across the globe, this is far from being a completed task. For many areas, species' range-maps are very often scarce or non-existent, and the study of biodiversity distribution has to rely on generally scant and scattered sampling records that are used to generate distribution maps through predictive modelling techniques. Still, it is critical that in those situations some sort of survey completeness analysis be carried out, not only as a way to help focus future samplings toward species groups and areas poorly surveyed, but also to allow balancing the interpretation of the patterns with data limitations, as shown here for Bioko. The patterns of species richness, endemism and threatened species we have described here represent a first approximation to the distribution of biodiversity in this island. Future field samplings, especially for plants, will render diversity models more adjusted to the biological reality of the study area. Until then, our results can provide useful baseline information to the establishment of conservation priorities in the island.

\section{Acknowledgements}

We are indebted to Luis Cayuela for his comments on the manuscript. NZ-C wants to thank the Spanish Agency for Development and Cooperation (AECID) for providing financial support to this study through a MAE/AECID Grant. Work by MR and MÁR was supported by the Spanish Ministry of Science and Innovation (grant CGL2006-03000/ BOS to MÁR).

\section{References}

Aedo C, Tellería T \& Velayos M, 1999. Bases documentales para la flora de Guinea Ecuatorial, plantas vasculares y hongos. Madrid: Consejo Superior de Investigaciones Científicas (CSIC) y Agencia Española de Cooperación Internacional (AECI).

Albrechtsen L et al., 2007. Faunal loss from bushmeat hunting: empirical evidence and policy implications in Bioko Island. Environmental Science \& Policy, 10:654-667.

Aldasoro JJ, Cabezas F \& Aedo C, 2004. Diversity and distribution of ferns in sub-Saharan Africa, Madagascar and some islands of the South Atlantic. Journal of Biogeography, 31:1579-1604.

Brooks TM, Da Fonseca GAB \& Rodrigues ASL, 2004. Protected areas and species. Conservation Biology, 18:616-618. 
Burgess $\mathrm{N}$ et al., 2006. Factoring species, non-species values and threats into biodiversity prioritisation across the ecoregions of Africa and its islands. Biological Conservation, 127:383-401.

Butynski T \& Koster S, 1994. Distribution and conservation status of primates in Bioko Island, Equatorial Guinea. Biodiversity and Conservation, 3:893-909.

Cabezas F, 2006. Las familias Bromeliaceae, Velloziaceae, Strelitziaceae, Musaceae, Zingiberaceae, Costaceae, Cannaceae, Marantaceae, Cyperaceae, Juncaceae, Commlinaceae, Eriocaulaceae y Xyridaceae de la Flora de Guinea Ecuatorial. [PhD Dissertation]. Madrid: Universidad Complutense de Madrid.

Chefaoui RM \& Lobo JM, 2008. Assessing the effects of pseudoabsences on predictive distribution model performance. Ecological Modelling, 210:478-486.

Elith J et al., 2006. Novel methods improve prediction of species' distributions from occurrence data. Ecography, 29:129-151.

Faria D et al., 2006. Bat and bird assemblages from forests and shade cacao plantations in two contrasting landscapes in the Atlantic Forest of southern Bahia, Brazil. Biodiversity and Conservation, 15:587-612.

Figueiredo E, 1994. Diversity and endemism of angiosperms in the Gulf of Guinea Island. Biodiversity and Conservation, 3:785-793.

Figueiredo E \& Gascoigne A, 2001. Conservation of pteridophytes in São Tomé e Príncipe (Gulf of Guinea). Biodiversity and Conservation, 10:45-68.

Harris GM, Jenkins CN \& Pimm SL, 2005. Refining biodiversity conservation priorities. Conservation Biology, 19:19571968.

Hortal J and Lobo JM, 2006. Towards a synecological framework for Systematic Conservation Planning. Biodiversity Informatics, 3:16-45.

Hortal J, Lobo JM and Jiménez-Valverde A, 2007. Limitations of biodiversity databases: case study on seed-plant diversity in Tenerife, Canary Islands. Conservation Biology, 21:853-863.

Jiménez-Valverde A, Lobo JM \& Hortal J, 2008. Not as good as they seem: the importance of concepts in species distribution modelling. Diversity and Distributions, 14:885-890.
Lobo JM et al., 2007. How does the knowledge about the spatial distribution of Iberian dung beetle species accumulates over time? Diversity and Distributions, 12:521-524.

Moreno CE \& Halffter G, 2000. Assessing the completeness of bat biodiversity inventories using species accumulation curves. Journal of Applied Ecology, 37:149-158.

Myers N, et al., 2000. Biodiversity hotspots for conservation priorities. Nature, 403:853-858.

Nix HA, 1986. A biogeographic analysis of Australian elapid snakes. In Longmore R (ed.). Atlas of Elapid Snakes of Australia. Canberra: Australian Flora and Fauna Series Number 7 - Australian Government Publishing Service. p. 4-15.

Nosti J, 1942. Geobotánica colonial. Notas geográficas, físicas y económicas de los territorios españoles del Golfo de Guinea. Madrid: Instituto de Estudios Africanos (CSIC).

Peet NP \& Atkinson BW, 1994. The biodiversity and conservation of the birds of São Tomé and Príncipe. Biodiversity and Conservation, 3:851-867.

Pérez del Val J, 1996. Las Aves de Bioko, Guinea Ecuatorial - Guía de Campo. León, Spain: Edilesa.

Pérez del Val J et al., 1994. Species richness and endemism in birds in Bioko. Biodiversity and Conservation, 3:868-892.

Tchouto MGP et al., 2006. Biodiversity hotspots and conservation priorities in the Campo-Maan rain forests, Cameroon. Biodiversity and Conservation, 15:1219-1252.

Velayos M, Aedo C \& Pérez-Viso R, 2001. Check-list of the Pteridophytes of Equatorial Guinea. Belgian Journal of Botany, 134:145-191.

Zafra-Calvo N et al., 2010a. Prioritizing areas for conservation and vegetation restoration in post-agricultural landscapes: a Biosphere Reserve plan for Bioko, Equatorial Guinea. Biological Conservation, 143:787-794.

Zafra-Calvo N, Rodríguez MÁ \& Lobo JM, 2010b. Discerning the impact of human-mediated factors on biodiversity using bioclimatic envelope models and partial regression techniques. Diversity and Distributions, 16:300-309.

Zapfack L et al., 2002. The impact of land conversion on plant biodiversity in the forest zone of Cameroon. Biodiversity and Conservation, 11:2047-2061. 